\title{
ATIVIDADE DE $\beta$-GLUCOSIDASES EM EXTRATO ENZIMÁTICO OBTIDO DE AMÊNDOAS DE PÊSSEGO ${ }^{1}$
}

\author{
ROSEANE FARIAS D'AVILA², RUI CARLOS ZAMBIAZI' ${ }^{3}$, \\ PRISCILA SILVA DE SÁ ${ }^{4}$, RICARDO PERAÇA TORALLES ${ }^{5}$
}

RESUMO-A presença dos glicosídeos cianogênicos amigdalina e prunassina, e de $\beta$-glucosidases as quais hidrolisam estas moléculas, faz com que a amêndoa de pêssego apresente potencial toxidez pela possibilidade de liberação de cianeto de hidrogênio, impossibilitando a utilização da amêndoa e de subprodutos como alimentos. Até o presente, não há dados disponíveis na literatura sobre as condições de hidrólise das enzimas presentes neste material. Este trabalho visou a mensurar o conteúdo de amigdalina, e as condições ideais de $\mathrm{pH}$, temperatura e concentração do substrato de extrato bruto de $\beta$-glucosidases para a atuação enzimática, em amêndoas de pêssego. Os resultados demonstraram a presença do glicosídeo na amêndoa de pêssego em níveis semelhantes aos relatados para outras amêndoas. Quanto à atividade de $\beta$-glucosidase, a enzima apresentou $\mathrm{K}_{\mathrm{m}}$ e $\mathrm{V}_{\text {máx }}$ de 2,7 mmol. $\mathrm{L}^{-1}$ de amigdalina e $0,1407 \mathrm{mmol}$ de glicose. $\mathrm{min}^{-1} . \mathrm{mg}^{-1}$ de proteína, respectivamente, valores que indicam menor afinidade pelo substrato amigdalina do que de enzimas purificadas que catalisam as mesmas reações. $\mathrm{O}$ pH ótimo da enzima foi o 7,0, porém entre 5,0; 6,0 e 8,0 ainda ocorre elevada atividade. A enzima demonstrou estabilidade nas temperaturas empregadas neste estudo, apresentando máxima atividade a $60^{\circ} \mathrm{C}$. Deste modo, o uso destas alterações não é suficiente para inativação enzimática e utilização segura das amêndoas de pêssego.

Termos para indexação: amigdalina, liberação de cianeto de hidrogênio, Prunus persica.

\section{$\beta$-GLUCOSIDASE ACTIVITY IN ENZYME EXTRACT OBTAINED FROM PEACH KERNEL}

\begin{abstract}
The presence of cyanogenic glycoside amygdalin and prunasin, and of $\beta$-glucosidases which hydrolyze these molecules, causes potential toxicity in peach kernel by the possible hydrogen cyanide release, disabling the use of the kernel and their sub-products as foods. Until now, no data are available in the literature on the conditions of the enzymes hydrolysis present in this material. This study aimed to measure the amygdalin content, and the optimal conditions of $\mathrm{pH}$, temperature and substrate concentration of $\beta$-glucosidases crude extract for the enzymatic activity. The results showed the presence of the glycoside in peach almond in levels similar to those found for other almond kernels. Regarding the activity of $\beta$-glucosidase, the enzyme showed $\mathrm{K}_{\mathrm{m}}$ and $\mathrm{V}_{\max }$ of $2.7 \mathrm{mmol} \mathrm{L}^{-1}$ of amygdalin and $0.1407 \mathrm{mmol}$ of glicose. $\mathrm{min}^{-1} . \mathrm{mg}^{-1}$ of protein respectively, values that indicate lower affinity for amygdalin substrate than purified enzymes that catalyze the same reaction. The optimum $\mathrm{pH}$ of the enzyme was 7.0, but between 5.0,6.0 and 8.0 high activity still occurs. The enzyme showed stability at the temperatures employed in this study, with maximum activity at $60^{\circ} \mathrm{C}$. Thus, the use of these changes is not sufficient for enzyme inactivation and safe use of peach kernels.
\end{abstract}

Index terms: amygdalin, hydrogen cyanide release, Prunus persica.

\footnotetext{
${ }^{1}$ (Trabalho 182-14). Recebido em: 06-06-2014. Aceito para publicação em: 08-06-2015.

${ }^{2}$ Mestre em Ciência e Tecnologia de Alimentos, Universidade Federal de Pelotas, Departamento de Ciência e Tecnologia Agroindustrial, 96010-900, Capão do Leão - RS, Brasil. roseane.davila@gmail.com

${ }^{3} \mathrm{PhD}$. Food and Nutritional Science, Docente, Universidade Federal de Pelotas, Centro de Ciências Químicas, Farmacêuticas e de Alimentos, 96010-900, Capão do Leão - RS, Brasil. zambiazi@gmail.com

${ }^{4}$ Tecnóloga em Gestão Ambiental e Saneamento Ambiental, Instituto Federal Sul Riograndense, Departamento de Química, 96015-360, Pelotas - RS, Brasil. priscila.ifsul@gmail.com

${ }^{5}$ Doutor em Ciência e Tecnologia Agroindustrial, Docente, Instituto Federal Sul Riograndense, Departamento de Química, 96015-360, telefone para contato: (53) 32270553 .Pelotas - RS, Brasil. toralles@pelotas.ifsul.edu.br
} 


\section{INTRODUÇÃO}

O pêssego (Prunus persica) classifica-se como uma fruta do tipo drupa de endocarpo lenhoso, pertencente à família Rosaceae (DARDICK; CALLAHAN, 2014). No Brasil, é produzido principalmente nos estados do Sul, devido ao clima mais frio, sendo que grande parte das frutas colhidas é destinada à industrialização. Durante o processamento de conservas, a fruta passa por operações de corte e descaroçamento. O caroço resultante é geralmente considerado como resíduo industrial, embora possa também ser incinerado para produção de energia térmica (MIGLIORINI et al., 2013), na alimentação animal ou como matéria-prima para a obtenção de um material poroso que pode ser utilizado em filtros de tratamento de efluentes. A amêndoa presente no interior do caroço apresenta potencial para utilização como alimento, devido aos teores de proteínas e lipídeos, de 21 e $25 \%$, respectivamente, sendo o restante representado pela umidade, superior a $25 \%$, fibras e carboidratos, que totalizam 24\% (MEZZOMO, 2008).

Em frutas de caroço, que podem acumular altos níveis do dissacarídeo cianogênico (R)amigdalina (O- $\beta$-D-gentibiosídeo de (R)mandelonitrila), ocorre a ação de $\beta$-glucosidase (EC 3.2.1.21) e hidroxinitrilo liase (RODRIGUEZ et al., 2009), sendo as glucosidases as que atuam na catálise da quebra de ligações glicosídicas em oligossacarídeos ou glicoconjugados, podendo ser específicas para moléculas de açúcares que possuem determinada configuração, posição e número de grupos hidroxílicos (MELO; CARVALHO, 2006).

Os glicosídeos cianogênicos, dentre os quais a amigdalina, são compostos de defesa das plantas, que estão na forma glicosilada e, assim, temporariamente inativos, até que ocorra a ação de enzimas que hidrolisam a molécula (BOLARINWA; ORFILA; MORGAN, 2015). A hidrólise da amigdalina ocorre primeiramente pela ação de amigdalina hidrolase, que age sobre a ligação $\beta$ 1-6 entre as duas glicoses. A molécula de prunassina liberada consiste no substrato para a enzima prunassina hidrolase, produzindo uma molécula de glicose e uma de mandelonitrila, que pode ser dissociada espontaneamente ou pela ação da enzima mandelonitrila liase, liberando íons cianeto (MORANT et al., 2008b). O cianeto possui potencial tóxico porque inativa o complexo citocromo oxidase da respiração celular (MORANT et al., 2008a).

A enzima prunassina hidrolase, encontrada em amêndoas amargas e doces, está localizada em vesículas específicas presentes em células do endosperma, nucelo e tegumento (SÁNCHEZ-
PEREZ et al., 2012), separadas dos glicosídeos cianogênicos, estocados no vacúolo celular (MORANT et al., 2008a). Ocorrendo a ruptura celular, os glicosídeos cianogênicos entram em contato com $\beta$-glucosidades, o que ocasiona a hidrólise destes compostos (MORANT et al., 2008b).

Assim, este estudo teve por objetivo caracterizar as amêndoas de pêssego quanto aos seus componentes que estão envolvidos na formação de cianeto de hidrogênio, mensurando a quantidade de amigdalina, presente nas amêndoas, e avaliando as características ótimas de atividade enzimática, incluindo a concentração do substrato, temperatura e $\mathrm{pH}$.

\section{MATERIAL E MÉTODOS}

\section{amêndoas}

Determinação do teor de amigdalina nas

O material de estudo foi obtido de indústrias produtoras de pêssego em calda da cidade de PelotasRS (Oderich e Icalda), proveniente de frutas de cultivares precoces e tardias, da safra de 2011/2012. Primeiramente, os caroços de pêssego foram secos por $24 \mathrm{~h}$ a aproximadamente $45^{\circ} \mathrm{C}$, em estufa com circulação de ar. Após, foram quebrados para a remoção das amêndoas, utilizando equipamento desenvolvido em laboratório, modelo de triturador de rolos canelados, com $1,29 \mathrm{~kW}$ de potência e capacidade de operação equivalente a $400 \mathrm{~kg} \cdot \mathrm{h}^{-1}$. Os caroços que permaneceram inteiros foram desintegrados manualmente com auxílio de um martelo. As amêndoas foram conservadas a $-25^{\circ} \mathrm{C}$ até o momento das análises.

Para realizar as análises, pesaram-se 2,5 g de amêndoa de pêssego triturada, que foi homogeneizada durante 2 horas com $15 \mathrm{~mL}$ de etanol grau HPLC. A amostra foi colocada em banho ultrassônico durante 30 minutos, após foi filtrada,utilizando papel-filtro qualitativo de 80 g.m $\mathrm{m}^{-2}$ de espessura, $205 \mu \mathrm{m}$ de gramatura e poros de $14 \mu \mathrm{m}$, e transferida para balão volumétrico de $20 \mathrm{~mL}$. Uma alíquota da amostra foi centrifugada em tubo de Eppendorf, a 7.000 rpm, durante 10 minutos (metodologia adaptada de ZHOU et al., 2007). O sobrenadante foi injetado, em quantidade de $10 \mu \mathrm{L}$, em Cromatógrafo Líquido de Alta Eficiência (HPLC) Shimadzu, com injetor automático, detector UV-VIS a $220 \mathrm{~nm}$, com coluna de fase reversa RP-18 CLC-ODS (5 $\mu \mathrm{m}, 4,6$ mm x $150 \mathrm{~mm}$ ), com fase estacionária octadecil e coluna de guarda CLC-GODS, ambas localizadas em forno a $25^{\circ} \mathrm{C}$. O fluxo empregado foi de $0,8 \mathrm{~mL} \cdot \mathrm{min}^{-1}$, utilizando eluição isocrática de $80: 20$, água ultrapura e metanol grau HPLC, segundo metodologia de Du 
et al. (2005), adaptada. A identificação da amigdalina foi realizada pela comparação entre o tempo de retenção do pico da amostra e o do respectivo padrão; e a quantificação foi realizada pela relação entre a área do pico de interesse e a curva de calibração do padrão, previamente construída. Os resultados foram expressos em mg. $\mathrm{g}^{-1}$ de amostra.

\section{Extração da enzima}

O procedimento para a extração da enzima consistiu na homogeneização de $100 \mathrm{~g}$ de amêndoas de pêssego trituradas em $300 \mathrm{~mL}$ de bicarbonato de sódio $\left(\mathrm{NaHCO}_{3}\right)$ 0,1 mol.L $\mathrm{L}^{-1}$. O extrato permaneceu em banho-maria durante 24 horas, a $40 \pm 2{ }^{\circ} \mathrm{C}$ (adaptado de TIMERMAN, 2012). Após este período, foi resfriado à temperatura ambiente e centrifugado a $10.000 \mathrm{rpm}$ durante 10 minutos. Por meio de ensaios preliminares, observou-se que a atividade enzimática deste extrato bruto não diferiu significativamente da apresentada pelo extrato em diluição 1:9 (extrato bruto: água). Deste modo, o extrato diluído na proporção 1: 9 (extrato: água) foi utilizado para as análises.

\section{Determinação do teor de proteínas no extrato}

A determinação do teor de proteínas do extrato enzimático foi realizada de acordo com o método de biureto e albumina de sérum bovino (BSA) para construção de curva-padrão (ROBINSON; HOGDEN, 1940). A leitura de absorbância foi realizada em espectrofotômetro Jenway 6705 UV/ VIS a $540 \mathrm{~nm}$.

\section{Efeito da concentração do Substrato}

$\mathrm{O}$ método consistiu na adição em tubos de ensaio de $1 \mathrm{~mL}$ do extrato enzimático, $1 \mathrm{~mL}$ de tampão de McIlvaine $\mathrm{pH}$ 6,0, e $1 \mathrm{~mL}$ das soluções de amigdalina nas concentrações de 4,4; 8,7; 13,1; 17,$5 ; 21,9 ; 26,2$ e 30,6 mmol. $L^{-1}$. Em seguida, as amostras foram incubadas em banho-maria durante $10 \min$ a $35^{\circ} \mathrm{C}$ para que ocorresse a ação enzimática. Após este período, foi adicionado 1 $\mathrm{mL}$ de ácido 3,5-dinitrosalicílico (3,5-DNS), o que reage com os açúcares redutores presentes no meio, durante reação em banho-maria fervente, durante 5 minutos, e, posteriormente, mais $6 \mathrm{~mL}$ de água foram adicionados. Devido à forte coloração vermelha apresentada na maioria dos tubos, foi necessária a diluição dos meios, que foi realizada por meio da adição de $1 \mathrm{~mL}$ da solução a $10 \mathrm{~mL}$ de água. A leitura de absorbância foi então realizada a $490 \mathrm{~nm}$. A curva de calibração foi construída a partir de soluções de glicose com concentrações de até 5.000 ppm. Assim como nos ensaios das enzimas, as soluções foram diluídas em 1: 10 de água.

\section{Efeito do $\mathrm{pH}$}

$\mathrm{O}$ efeito do $\mathrm{pH}$ foi avaliado pela adição respectiva de $1 \mathrm{~mL}$ dos tampões de McIlvaine $\mathrm{pH} 3$; 4; 5; 6; 7 e 8 , a $1 \mathrm{~mL}$ do extrato enzimático e $0,5 \mathrm{~mL}$ de solução de amigdalina $10,9 \mathrm{mmol} . \mathrm{L}^{-1}$, em tubo de ensaio, que foi levado a banho-maria a $35^{\circ} \mathrm{C}$, durante 10 minutos. Após a adição de $1 \mathrm{~mL}$ de reagente ácido 3,5-dinitrosalicílico, as amostras permaneceram durante 5 minutos em banho-maria fervente e adicionaram-se 6,5 mL de água (BERNFELD, 1955). Antes da leitura, ocorrida a $490 \mathrm{~nm}$, procedeu-se à diluição da solução na proporção de 1: 10 (amostra: água).

\section{Efeito da Temperatura}

Foi avaliado pela adição de $1 \mathrm{~mL}$ de tampão de McIlvaine $\mathrm{pH}$ 6,0 em tubo de ensaio, juntamente com 0,5 mL de solução de amigdalina 10,9 mmol. $\mathrm{L}^{-1}$ e $1 \mathrm{~mL}$ do extrato enzimático. A partir daí, as amostras foram incubadas a $10 ; 20 ; 30$; 40; 50; 60 e $70^{\circ} \mathrm{C}$, durante 10 minutos, e o mesmo procedimento descrito para o efeito do $\mathrm{pH}$ foi utilizado (BERNFELD, 1955).

\section{Análise estatística}

Os parâmetros $\mathrm{K}_{\mathrm{m}}$ e $\mathrm{V}_{\text {max }}$ foram estimados através de Software SigmaPlot 10.0, utilizando modelo de Henri-Michaelis-Menten. O intervalo de confiança entre as repetições para efeito do substrato, $\mathrm{pH}$ e temperatura foi calculado utilizado o programa The Sas System for Windows Versão 8. Os gráficos foram construídos a partir do Software SigmaPlot 10.0 .

\section{RESULTADOS E DISCUSSÃO}

As amêndoas de pêssego apresentaram quantidades de 0,44 $\pm 0,08 \mathrm{mg} \cdot \mathrm{g}^{-1}$ (base seca) de amigdalina. $\mathrm{O}$ cromatograma de identificação do componente pode ser visualisado na Fig. 1. A identificação foi realizada pela comparação com o tempo de retenção do padrão, com pico no tempo de retenção de 10,0 min, o que é condizente com os valores encontrados por Kim et al. (2014), de 0,486 e 0,548 mg. $\mathrm{g}^{-1} \mathrm{de}$ amigdalina em pêssegos não maduros, de cultivares produzidas no Japão.

As amêndoas de damasco contêm cerca de 0,23 a $0,69 \mathrm{mg} \cdot \mathrm{g}^{-1}$, em base seca, de glicosídeos cianogênicos. Como o pêssego, os principais glicosídeos presentes no damasco são a amigdalina e a prunassina (TUNÇEL et al., 1998). Os valores 
encontrados pelos autores são condizentes com os encontrados neste estudo. Swain et al. (1992) demonstraram que os níveis de prunassina e amigdalina apresentam alterações durante o grau de maturação de cerejas-pretas. Inicialmente, não ocorre a presença de amigdalina, porém à medida que a maturação ocorre, o conteúdo do glicosídeo apresenta acentuado acréscimo, superior a $3 \mu \mathrm{mol}$.semente ${ }^{-1}$, aos 76 dias de maturação, enquanto o conteúdo deste glicosídeo na prunassina apresenta queda progressiva até teores próximos a zero. No pêssego, há maior acúmulo de matéria seca no caroço, em frutos de ciclo longo,do que nos de ciclo médio, havendo incremento de $50 \%$ no valor, no período dos 135 até os 180 dias após a antese (SILVA et al., 2013). O tamanho máximo da amêndoa ou semente é encontrado na fase de endurecimento do caroço, tendo algumas variedades aumentos pouco significativos de matéria seca após esse período (BRUNA; MORETO, 2011), podendo estes referirem-se a alterações de metabólitos durante o amadurecimento da fruta.

Extratos aquosos de raízes, caules e folhas de C. spitacus (Jacq). Sw possuem a presença de heterosídeos cianogênicos (PAES;MENDONÇA; CASAS, 2013), não representando um meio eficiente para a remoção destes compostos no processamento de extratos. Certos alimentos, como a mandioca, podem passar por processamento a temperaturas elevadas para promover a volatização do ácido cianídrico, porém tal processo inativa a enzima responsável pela sua produção (SILVA; FELIPINI, 2011). Os fatores $\mathrm{pH}$ e temperatura de processo são críticos para o processamento de produtos derivados de mandioca, que possui o cianosídeo glicogênico linamarina, uma vez que a etapa de ação de $\beta$-glucosidases é responsável pela sua detoxificação (CHISTÉ; COHEN, 2011).

A concentração do substrato utilizada neste estudo foi de até 10,2 mmol. $\mathrm{L}^{-1}$ de amigdalina no meio reacional. Porém, a partir de 7,3 mmol.L-1, observou-se queda dos valores, possivelmente pela saturação das enzimas com o substrato, atingindo-se nessa concentração a $\mathrm{V}_{\text {máx }}$ (velocidade máxima), momento em que todas as enzimas estão combinadas com o substrato (SIQUEIRA et al., 2011). Na Fig. 2, estão os dados de atividade enzimática específica (mmol de glicose. $\mathrm{min}^{-1} \cdot \mathrm{mg}^{-1}$ de proteína), calculados com concentração do substrato até $7,3 \mathrm{mmol} \cdot \mathrm{L}^{-1}$. O teor de proteínas no extrato enzimático foi de $15,54 \mathrm{mg}$ de proteínas por $\mathrm{mL}$. O extrato bruto de $\beta$-glucosidases obtido a partir de cerejas-doces possui teor de proteínas total de 2,63 mg de proteínas totais, mensurado pelo método de Bradford, utilizando albumina como padrão (GERARDI et al., 2001). O extrato bruto obtido pelo autor utilizava pó de ace- tona, que faz com que as amostras não contenham pigmentos que possam interferir em métodos colorimétricos. O maior teor encontrado neste estudo para o extrato bruto pode estar relacionado ao método de extração, à presença de diferentes componentes na amêndoa de pêssego, ao alto teor de proteínas ou à presença de impurezas.

Segundo o modelo, os parâmetros estimados para o extrato enzimático foram de $\mathrm{V}_{\text {máx }}=0,1407$ (mmol de glicose produzida.min ${ }^{-1}$ de reação. $\mathrm{mg}^{-1}$ de enzima) e $\mathrm{K}_{\mathrm{m}}=2,700$ mmol. $\mathrm{L}^{-1}$. As $\beta$-glucosidases extraídas de sementes de maçã e de amêndoas de pêssego parecem possuir preferência por glicosídeos alquil de cadeia média como substratos, com estabilidade semelhante à de glucosidades comerciais (YU et al., 2007).

Kuroki e Poulton(1987) estudaram as enzimas prunassina hidrolase I, IIa e IIb, e obtiveram valor de $\mathrm{K}_{\mathrm{m}}$ entre 1,3-2,3 $\mathrm{mM}$ e $\mathrm{V}_{\text {máx }}$ entre 13,9 e 54,2 (mmol de glicose. $\mathrm{h}^{-1} \cdot \mathrm{mg}^{-1}$ proteína), dependendo da enzima. As enzimas prunassina hidrolases apresentaram preferência de hidrólise pelo substrato (R)-prunassina e inativação frente aos demais glicosídeos cianogênicos,como (R)-amigdalina, linustatina, neolinustatina, (S)-dhurrina e linamarina. Ensaios realizados por diversos autores demonstram que prunassinas hidrolases altamente purificadas exibem alta afinidade pelo substrato (R)-prunassina e são completamente inativas quando em presença de (R)-amigdalina (ZHOU et al., 2007).

As isoenzimas amigdalina hidrolases I', I, II e II' extraídas de cerejas-pretas foram caracterizadas quanto a seus parâmetros cinéticos a $\mathrm{pH} 5$, e apresentaram $\mathrm{K}_{\mathrm{m}}$ entre 1,65-2,20 e velocidade máxima de reação entre 30,3 e $33,5 \mathrm{mmol}$ glicose $\mathrm{h}^{-1} \cdot \mathrm{mg}^{-1}$ (LI et al., 1992).

Valores baixos de $\mathrm{k}_{\mathrm{m}}$, em comparação com enzimas obtidas de outras fontes que agem sobre os mesmos substratos, indicam maior afinidade de ligação da enzima com o substrato (BINATE et al., 2008). Os valores das constantes cinéticas $\mathrm{K}_{\mathrm{m}} \mathrm{e} \mathrm{V}_{\text {máx }}$ encontrados neste estudo representam um grupo de enzimas que hidrolisam as ligações glicosídicas da molécula de amigdalina, podendo estar presentes no extrato obtido uma mistura de diferentes isozimas de amigdalina e prunassina hidrolase. Apesar de $\mathrm{K}_{\mathrm{m}}$ e $\mathrm{V}_{\text {máx }}$ estarem acima dos valores encontrados pelos autores, citados em trabalhos com cerejas-pretas, as enzimas apresentaram afinidade relativamente alta pelo substrato, uma vez que não foram purificadas. $\mathrm{O}$ teor de proteínas em extratos brutos é muito mais superior do que em extratos purificados. À medida que Gerardi et al. (2001) purificaram o extrato bruto de $\beta$-glucosidase, o teor reduziu-se aproximadamente 
pela metade, após precipitação com $\left(\mathrm{NH}_{4}\right)_{2} \mathrm{SO}_{4}$; e foi 13 vezes menor após isolamento por cromatografia de troca iônica, e 25 vezes menor após separação por cromatografia de exclusão de tamanho. As enzimas presentes nos extratos demonstraram-se estáveis a uma ampla faixa de $\mathrm{pH}$ (Fig. 3), com atividade máxima ao $\mathrm{pH}$ de 5,0 a 7,0, sendo que a atividade ao $\mathrm{pH} 7$ difere significativamente da observada em pH 8. A atividade enzimática em diferentes pHs está relacionada com o balanço protonação/mudança conformacional (COLUSSI et al., 2015).

A atividade das enzimas prunassina hidrolase I, IIa e IIb, extraídas de cerejas-pretas atinge seu valor máximo ao valor de $\mathrm{pH} 5,0$, em tampão citrato-fosfato (KUROKI; POULTON, 1987). Nas amigdalinas hidrolases de mesma fonte, o pico da atividade enzimática apresenta-se entre os pHs 4,55,5 (LI et al., 1992). Os resultados encontrados no presente estudo sugerem que as enzimas prunassina e amigdalina hidrolase de amêndoas de pêssego possuem atividade enzimática em $\mathrm{pH}$ diferente dos encontrados em estudos similiares com cerejas-pretas, ou tal fato pode ser devido à presença de enzimas diferentes nas amêndoas de pêssego que possam ter maior atividade nas faixas de $\mathrm{pH}$ citadas.

Haque e Bradbury (2002), estudando um método de análise de cianeto total em plantas, cujo princípio é a hidrólise dos glicosídeos cianogênicos por enzimas endógenas, demonstraram que o $\mathrm{pH}$ ótimo para a ação das enzimas e a consequente liberação de cianeto em caroços de pêssego são é de 5-6. Em pH 7; 8 e 9, foram encontrados conteúdos com cerca de $20 \%$ a menos de cianeto de hidrogênio formado.O efeito de diferentes temperaturas sobre a ação de $\beta$-glucosidases de amêndoas de pêssego pode ser observado na Fig. 4.

Neste estudo, as enzimas demonstraram-se resistentes às temperaturas mais altas testadas, apresentando a atividade máxima a $60^{\circ} \mathrm{C}$ e declínio após este ponto. Este resultado é semelhante ao encontrado para $\beta$-glucosidases comerciais extraídas de amêndoas amargas, onde a temperatura máxima de ação é de $60^{\circ} \mathrm{C}$, seguida por declínio a $70^{\circ} \mathrm{C}$ que se acentua a $80^{\circ} \mathrm{C}$ (YU et al., 2007).

A atividade de $\beta$-glucosidases presentes em méis, mensurada com o substrato p-nitrofenil- $\beta$-Dglucopiranosidase, demonstrou completa ou parcial inativação das enzimas em ensaios a $60^{\circ} \mathrm{C}$, indicando que, neste produto, a referida enzima é mais termolábil. Porém, as enzimas demonstraram ser mais estáveis em $\mathrm{pH}$ alcalino, com redução da atividade a partir de pH 9,0 (PONTOH; LOW, 2002). Gerardi et al. (2001) também utilizaram o substrato p-nitrofenil para mensurar a atividade de $\beta$-glucosidases presen- tes em cerejas-pretas, uma vez que a atividade destas enzimas no substrato atinge níveis semelhantes à de atividade em prunassina, de 54 e $57 \%$, em percentual de atividade relativo.

Tunçel et al. (1998) relatam que a enzima $\beta$-glucosidase endógena presente em amêndoa de damasco, somente apresenta $100 \%$ de perda de atividade após tratamento realizado a $100^{\circ} \mathrm{C}$ por 20 minutos. Porém, utilizando o binômio $100^{\circ} \mathrm{C}$ e 10 minutos, a taxa de glicosídeos cianogênicos degradados após 2 horas de permanência em repouso, à temperatura ambiente, foi 20 vezes inferior quando comparada com a amostra que não passou por branqueamento. Em estudo comparando a estabilidade de extratos brutos de glucosidases a $50^{\circ} \mathrm{C}$, foi encontrado que as enzimas extraídas de amêndoas de pêssego foram as que possuíram maior estabilidade à temperatura por longos períodos. Apesar de o comportamento desta enzima e das enzimas comerciais extraídas de amêndoas ser o mesmo após $48 \mathrm{~h}$ de incubação, observou-se a preservação de aproximadamente $70 \%$ da atividade enzimática; em 72h, este valor reduziu-se para as enzimas comerciais e permaneceu para as enzimas presentes nas amêndoas de pêssego (YU et al., 2007). 


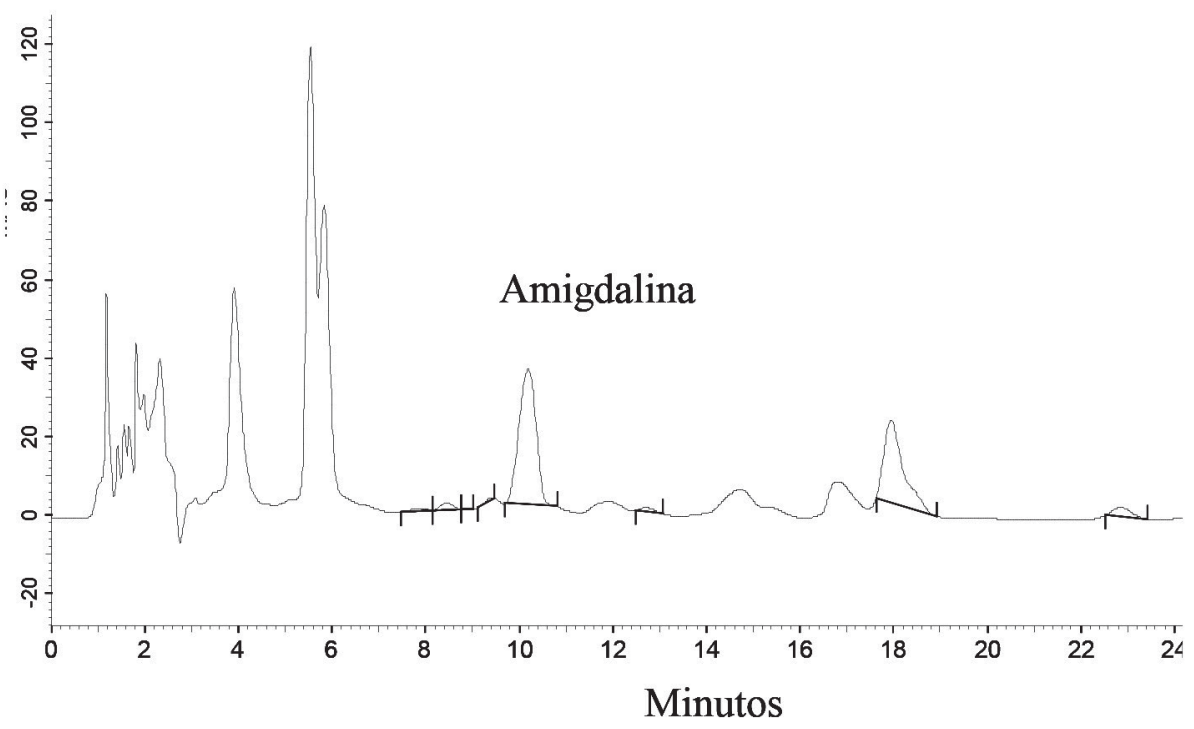

FIGURA 1- Cromatograma típico de amigdalina em amostra de amêndoa de pêssego, utilizando HPLC, equipado com coluna de fase reversa RP-18CLS-ODS. A separação foi realizada por eluição isocrática de água ultra pura: metanol a $0,8 \mathrm{~mL} \cdot \mathrm{min}^{-1}$. Detecção UV-Vis a $220 \mathrm{~nm}$

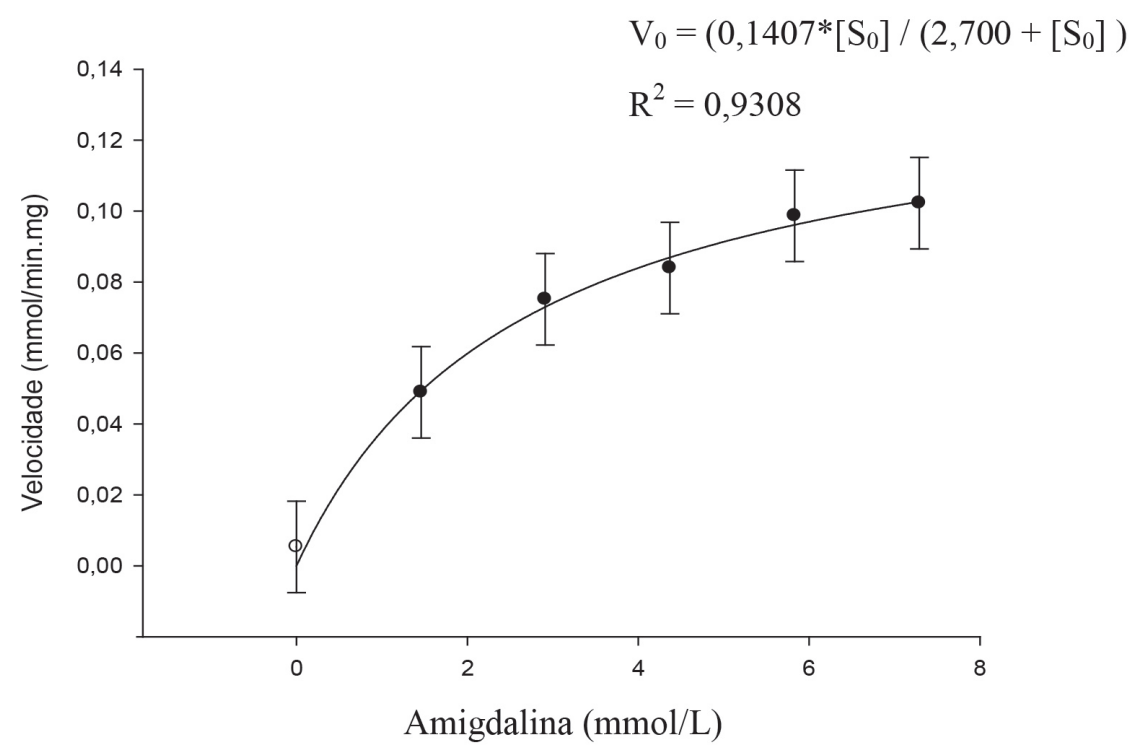

FIGURA 2- Atividade enzimática (a) e atividade enzimática específica (b) de $\beta$-glucosidase presente em amêndoa de pêssego, determinadas a pH 6 e temperatura de $35^{\circ} \mathrm{C}$, pela reação dos açúcares redutores liberados com o reagente 3,5-DNS. 


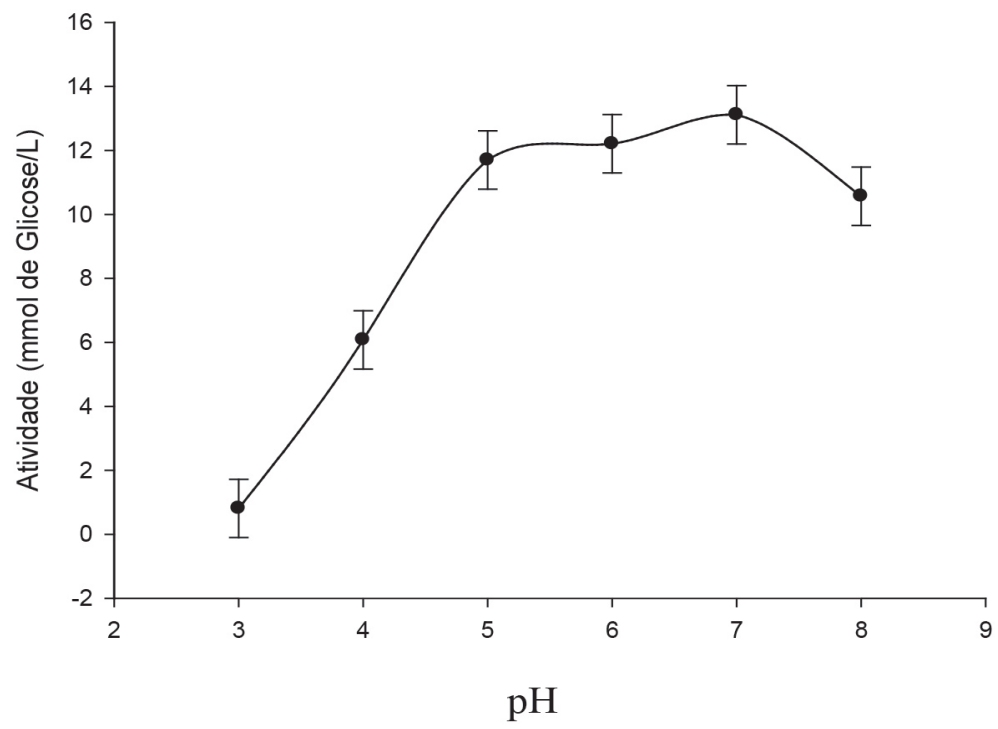

FIGURA 3 - Efeito do pH sobre a atividade enzimática de $\beta$-glucosidase extraída de amêndoa de pêssego, medida em mmol. $\mathrm{L}^{-1}$ de glicose, determinada utilizando solução de amigdalina $10,9 \mathrm{mmol} . \mathrm{L}^{-1}$ e temperatura de $35^{\circ} \mathrm{C}$, pela reação dos açúcares redutores liberados com o reagente 3,5-DNS.

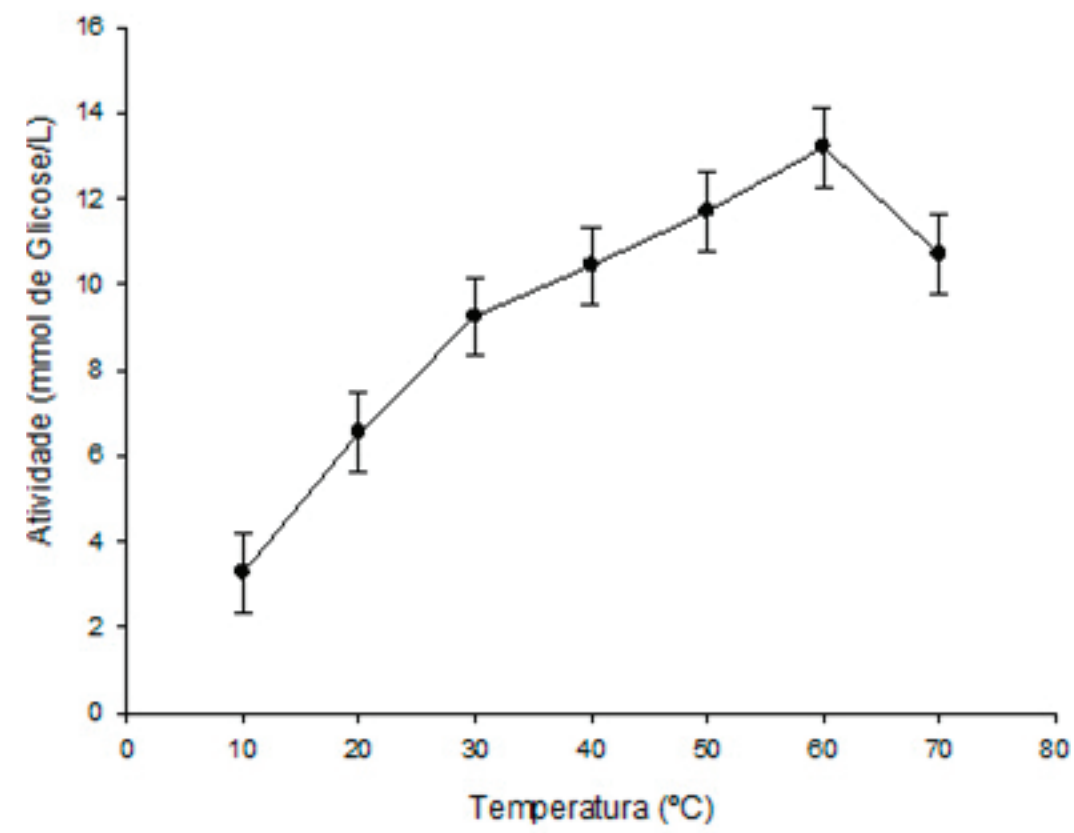

FIGURA 4- Efeito da temperatura sobre a atividade enzimática de $\beta$-glucosidase extraída de amêndoa de pêssego, medida em mmol. $\mathrm{L}^{-1}$ de glicose, determinada utilizando solução de amigdalina 10,9 mmol. $\mathrm{L}^{-1} \mathrm{e} \mathrm{pH} \mathrm{6,} \mathrm{pela} \mathrm{reação} \mathrm{dos} \mathrm{açúcares} \mathrm{redutores} \mathrm{liberados} \mathrm{com} \mathrm{o} \mathrm{reagente} \mathrm{3,5-DNS.}$ 


\section{CONCLUSÕES}

A amêndoa de pêssego, resíduo da agroindustrialização de pêssegos, que poderia ser utilizada como subproduto, apresenta teores de amigdalina semelhante ao de outras amêndoas amargas, componente que precisa ser hidrolisado anteriormente ao consumo, para que o produto seja detoxificado. $\mathrm{O}$ extrato bruto de $\beta$-glucosidases apresentou afinidade pelo substrato, com valores de $\mathrm{K}_{\mathrm{m}}$ de $2,7 \mathrm{mM}$ de amigdalina e de $\mathrm{V}_{\text {máx }}$ de 0,1407 mmol de glicose. $\mathrm{min}^{-1} \cdot \mathrm{mg}^{-1}$ de proteína, com atividade a diferentes valores de $\mathrm{pH}$. O extrato demonstrou-se ativo mesmo às temperaturas mais elevadas testadas $\left(60^{\circ} \mathrm{C}\right)$. Os dados deste estudo demonstram a estabilidade das enzimas presentes na amêndoa de pêssego e indicam que, para utilização deste resíduo industrial como subproduto, devem ser considerados meios para a remoção das mesmas e dos glicosídeos cianogênicos, uma vez que a inativação pelos meios aqui testados exige alterações radicais no $\mathrm{pH}$ ou na temperatura.

\section{REFERÊNCIAS}

BERNFELD, P. Amylases, $\alpha$ and $\beta$. Methods in Enzymology, New York, v.1, p.149-158, 1955.

BINATE, S.; N'DRI, D.; TOKA, M.; KOUAME, P. Purification and characterization of two betaglucosidases from termite workers Macrotermes bellicosus (Termitidae: Macrotermitinae). Journal of Applied Biosciences, Nairobi, v.10, p.461-470, 2008.

BOLARINWA, I. F.; ORFILA, C.; MORGAN, M. R. A. Determination of amygdalin in apple seeds, fresh apples and processed apple juices. Food Chemistry, Berlin, v.170, p.437-442, 2015.

BRUNA, E. D.; MORETO, A. L. Desenvolvimento dos frutos de pêssego 'Aurora' e nectarina 'Sunraycer' no sul de Santa Catarina. Revista Brasileira de Fruticultura, Jaboticabal, v. 33, n. 1, p. 485-492, 2011.

CHISTÉ, R. C.; COHEN, K. O. Teor de cianeto total e livre nas etapas de processamento do tucupi. Revista do Instituto Adolfo Lutz, São Paulo, v.70, n.1, p.437-440, 2011.

COLUSSI, F.; SILVA, V. M.; MILlER, I.; OLIVERIA, L. C.; OLIVEIRA NETO, M.; SQUINA, F. M.; GARCIA, W. Oligomeric state and structural stability of two hyperthermophilic -glucosidases from Thermotoga petrophila. Amino Acids, Wien, v. 47, n. 5, p.937-948, 2015.
DARDICK, C.; CALLAHAN, A. M. Evolution of the fruit endocarp: molecular mechanisms underlying adaptations in seed protection and dispersal strategies. Frontiers in Plant Science, Lausanne, v. 5, n. 284, p.1-10, 2014.

DU, Q.; JERZ, G.; HE, Y.; LI, L. XU, Y.; ZHANG, Q.; ZHENG, Q.; WINTERHALTER, P.; ITO, Y. Semi-industrial isolation of salicin and amygdalin from plant extracts using slow rotary counter-current chromatography. Journal of Chromatography A, Amsterdam, v.1074, p.43-46, 2005.

GERARDI, C.; BLANDO, F.; SANTINO, A.; ZACHEO, G. Purification and characterization of a $\beta$-glucosidase abundantly expressed in ripe sweet cherry (Prunus avium L.) fruit. Plant Science, New York, v.160, p.795-805, 2001.

HAQUE, M. R.; BRADBURY, J. H. Total cyanide determination of plants and foods using the picrate and acid hydrolysis methods. Food Chemistry, Berlin, v.77, p.107-114, 2002.

KIM, H. R.; KIM, I. D.; DHUNGANA, S. K.; KIM, M. O.; SHIN, D. H. Comparative assessment of physicochemical properties of unripe peach (Prunus persica) and Japanese apricot (Prunus mume). Asian Pacific Journal of Tropical Biomedicine, Singapore, v.4, n.2, p.97-103, 2014.

KUROKI, G. W.; POULTON, J. E. Isolation and characterization of multiple forms of prunasin hydrolase from black cherry (Prunus serotina Ehrh.) seeds. Archives of Biochemistry and Biophysics, Amsterdam, v.255, n.1, p.19-26, 1987.

LI, C. P.; SWAIN, E.; POULTON, J. E. Prunus serotina amygdalin hydrolase and prunasin hydrolase. Plant Physiology, Chicago, v.100, p.282-290, 1992.

MELO, E. B.; CARVALHO, I. $\alpha$ e $\beta$-glucosidases como alvos moleculares para desenvolvimento de fármacos. Química Nova, São Paulo, v.29, n.4, p.840-843, 2006.

MEZZOMO, N. Óleo de amêndoa de pêssego: Avaliação técnica de extração, da qualidade dos extratos e parâmetros para ampliação de escala. 2008. 136 f. Dissertação (Mestrado em Engenharia de Alimentos) - Universidade Federal de Santa Catarina, Florianópolis, 2008. 
MIGLIORINI, M. V.; MORAES, M. S. A.; MACHADO, M. E.; CAMARÃO, E. B. Caracterização de fenóis no bio-óleo da pirólise de caroço de pêssego por GC/MS e GCxGC/TOFMS. Scientia Chromatographica, São Carlos, v. 5, n. 1, p.47-65, 2013.

MORANT, A. V.; BJARNHOLDT, N.; KRAGH, M. E.; KJAERGAARD, C. H.; JORGENSEN, K.; PAQUETTE, S. M.; PIOTROWSKI, M.; IMBERTY, A.; OLSEN, C. E.; MOLLER, B. L.; BAK, S. The $\beta$-glucosidases responsible for bioactivation of hydroxynitrile glucosides in Lotus japonicus. Plant Physiology,Chicago, v.147, p.1072-1091, 2008b.

MORANT, A. V.; JORGENSE, K.; JORGENSEN, C.; PAQUETTE, S. M.; SÁNCHEZ-PÉREZ, R.; MOLLER, B. L.; BAK, S. $\beta$-glucosidases as detonators of plant chemical defense. Phytochemistry, Chicago, v.69, p.1795-1813, 2008a.

PAES, L. S.; MENDONÇA, M. S.; CASAS, L. L. Aspectos estruturais e fitoquímicos de partes vegetativas de Costus spicatus (Jacq.) Sw. (Costaceae). Revista Brasileira de Plantas Medicinais, Botucatu, v.15, n.3, p.380-390, 2013.

PONTOH, J.; LOW, N. H. Purification and characterization of $\beta$-glucosidase from honey bees (Apis mellifera). Insect Biochemistry and Molecular Biology, Oxford, v.32, p.679-690, 2002.

ROBINSON, H. W.; HOFGEN, C. G. The biuret reaction in the determination of serum proteins. The Journal of Biological Chemistry, Baltimore, v.135, p.707-725, 1940 .

RODRIGUEZ, A. G.; TEIXEIRA, O. M. SALLES, F. G.; VITAL, J. P.; PEIXOTO, D. S. Bioensaio com Artemia salina para detecção de toxinas em alimentos vegetais. Estudos, Coimbra, v. 36, n.5/6, p.795-808, 2009.

SÁNCHEZ-PEREZ, R.; BELMONTE, F. S.; BORCH, J.; DICENTA, F.; MOLLER, B. L.; JORGENSEN, K. Prunasin hydrolases during fruit development in sweet and bitter almonds. Plant Physiology, Chicago, v.158, p.1916-1932, 2012.

SILVA, D. F.; COSTA E SILVA, J. O.; MATIAS, R. G. P.; RIBEIRO, M. R.; BRUCKNER, C.H. Curva de crescimento e padrão respiratório de frutos de genótipos de pessegueiro em região de clima subtropical. Revista Brasileira de Fruticultura, Jaboticabal, v. 35, n. 2, p.642-649, 2013.
SILVA, M. A.; FELIPINI, T. Voltatização do HCN durante o processo de fenação de ramas de mandioca (Manihot esculenta Crantz). Cadernos de pósgraduação da Fazu, Uberada, v.2, p.1-6, 2011.

SIQUEIRA, A. J. S.; AZEVEDO, A. M. P.; MATTOSDUTRA, A.; FIN, C. A.; LANDO, V. R.; ROTTA, L. N.; WINK, M. R.; BJERK, R. L.; FERRACINI, M. S. Determinação do Km e V Max: revisão e uma nova proposta. Ciência em Movimento, Porto Alegre, n.27, p.47-52, 2011.

SWAIN, E.; LI, C. P.; POULTON, J. E. Development of the potential for cyanogenesis in maturing black cherry (Prunus serotina Ehrh.) fruits. Plant Physiology, Chicago, v.98, p.1423-1428, 1992.

TIMERMAN, A. P. The isolation of invertase from baker's yeast - an introduction to protein purification strategies. In: AHMAD, R. Protein purification. Washignton: Hard Cover, 2012. 224 p.

TUNÇEL, G.; NOUT, M. J. R.; BRIMER, L. Degradation of bitter apricot seeds (Prunus armeniaca) by endogenous and added enzymes as affected by heat treatments and particle size. Food Chemistry, Berlin, v.63, n.1, p.65-69, 1998.

YU, H. L.; XU, J. H.; LU, W. Y.; LIN, G. Q. Identification, purification and characterization of $\beta$-glucosidase from apple seed as a novel catalyst for synthesis of $O$-glucosides. Enzyme and Microbial Technology, New York, v.40, p.354-361, 2007.

ZHOU, C.; CHEN, K.; SUN, C.; CHEN, Q.; ZHANG, W.; LI, X. Determinaton of oleanolic acid, ursolic acid and amygdalin in the flower of Eriobotrya japonica Lindl. by HPLC. Biomedical Chromatography, London, v.21, p.755-761, 2007. 